\title{
Research on Comprehensive Budget Management of Logistics Enterprises
}

\author{
Dandan Guo,*, Baojiang Geng ${ }^{1}$, Yuyang Wen ${ }^{2}$ \\ ${ }^{1}$ College of Tourism, Sichuan Agricultural University, Dujiangyan, China \\ ${ }^{2}$ School of Foreign Languages, Henan University of Urban Construction, Pingdingshan, China \\ *Corresponding author. Email:Ddan1102@126.com
}

\begin{abstract}
The comprehensive budget management as a management mechanism, existed synthetically in the strategy of the enterprise, in an important position. However, many logistics enterprises in China have encountered many similar problems in implementation of comprehensive budget management, and the results obtained are not ideal. In the face of a variety of internal and external factors, the enterprises did not pay attention to the problems or considered the budget brings too much inconvenience and constraints. So the enterprises began to go away from the original intention and reduced emphasis on budget management. On the basis of literature research, we visit many logistics enterprises to investigate, through in-depth interviews with logistics enterprise managers or employees, and from the perspective of logistics enterprises, this paper will discusses the problems that, existed in comprehensive budget management in enterprises, employees lack management awareness, the overall budget management system has a low level of information, the enterprises lack strategic management awareness, comprehensive budget control and assessment mechanism; and the enterprises can't divide the responsibilities clearly. I will give corresponding suggestions for the problems existing in the comprehensive budget management of logistics enterprises.
\end{abstract}

Keywords: Comprehensive Budget, Logistics Enterprises, Budget Management

\section{INTRODUCTION}

Budget management, which originated in the $1820 \mathrm{~s}$, is an important method of internal management control of enterprises and plays a vital role in the maturity and development of modern industrial and commercial enterprises. With the quick development of social productivity level and the increasingly fierce market competition, in order to improve their competitiveness and resist risks, enterprises constantly develop deep on functions, effect and scope of the budget management. In the circumstances, to the middle-late 20th century the new modern enterprise management mode of comprehensive budget management appeared, and it is highly valued and promoted by the managers of industrial and commercial enterprise groups [1]. In recent years, because of the sustainable development of the logistics industry, the potential of market development is constantly being tapped, the degree of specialization continues to increase, more and more enterprises entered the logistics market, and good conditions comprehensive budget management organization has been established that contain board with affiliated responsibilities institutions and functional department [2]. The comprehensive budget management as a management mechanism, existed synthetically in the strategy of the enterprise, in an important position. Its main function embodies in using budget to distribute and control enterprise resources scientifically, helping enterprise implement activities smoothly to achieve the anticipated target of the enterprise management [3]. However, budget management is widely used in the logistics industry, in the meantime it also encounters many problems, which affects its role in the enterprises.

\section{SIGNIFICANCE OF COMPREHENSIVE BUDGET MANAGEMENT}

\subsection{It can strengthen the enterprises to control the budget}

In order to cope with and solve the risks that enterprises often face in their daily operations, such as financial risks and legal risks, they will constantly accumulate experience to make predictions. This requires the enterprise to edit the budget, strictly 
implement the budget and control the budget, etc. In this series of links, an overall control system of pre-process, in-process and post-process is formed [4]. As a key component of enterprise internal control, comprehensive budget management can help enterprises to gradually strengthen the control and governance of the weak links in the enterprise, adjust or correct the estimation of some weak links accordingly, and finally increase the enterprise value [5]. At the same time, it will also help enterprises to create a set of rewards and punishments system in line with enterprise development, and find appropriate supervision methods for enterprise managers, so as to strengthen the effect of enterprise budget control.

\subsection{It is beneficial to the implementation of enterprise strategy}

When making strategic planning, enterprises usually focus on the enterprise strategy and take the enterprise strategy as the starting point. Budget is closely related to strategy, which is an indispensable part, as well as the detailed and explicit strategic planning. The plan with clear details is conducive to improving the effect of enterprise decision-making, and the operation degree of control can also be strengthened. Budgets also provide an enhanced or modified role in strategic planning. The company promotes the implementation of its strategy through budget targets. Budget targets are the basis of budget evaluation. Budget evaluation links performance compensation to ensure the realization of the strategy, so that the enterprise management can be penetrated among performance, strategy and budget, and comprehensive budget management can be carried out better [6].

\subsection{It will promote rational allocation of enterprise resources}

Enterprises continue to pursue development, but their resources are limited, and the growth of resources will never keep up with the growth of demand. When an enterprise conducts comprehensive budget management, budget assessment and evaluation is a very important step in the overall process. This key step will help the enterprise apply more scientific and accurate methods in budget management and operation status, so as to carry out qualitative and quantitative evaluation [7]. Budget evaluation is not only a very effective measure, can make budget management level promote reasonably, the limited resources of enterprise optimize configuration [8], but also can provide enterprises with information to analyze the performance indicators, and performance evaluation is an important source of conducted on employees to achievement evaluation. At this time of the enterprise managers can understand more the status of the performance.

\section{ANALYSIS OF CURRENT SITUATION OF OVERALL BUDGET MANAGEMENT OF LOGISTICS ENTERPRISES}

With the development of logistics enterprises, budget management is gradually implemented in logistics enterprises. The internal organizational system of logistics enterprises can be generally divided into administrative business department, business operation department and functional supervision department. Due to different specific situations of enterprises, the further division of each department is also different. The budget of logistics enterprises focuses on many aspects, including main business, other whole business, fixed cost, variable cost, assets and liabilities. Logistics enterprises comprehensively estimate and plan the assets, operation, capital and other aspects of a period of time, and determine the budget assumptions, etc., which are the test of the rich experience of budget decision makers and the control of the economic trend in a period of time to come. Once the final budget is formed, it will be distributed to all subordinate departments for implementation. The comprehensive budget management system is shown in Figure 1:

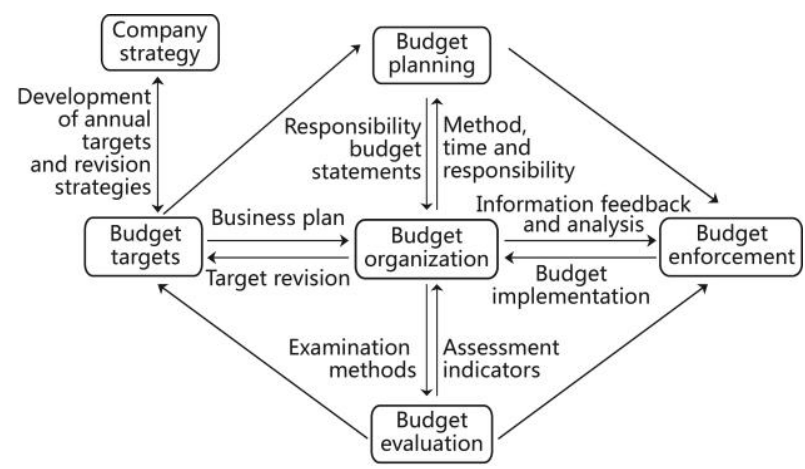

Figure 1 Comprehensive budget management system

\section{PROBLEMS IN THE OVERALL BUDGET OF LOGISTICS ENTERPRISES}

\subsection{Employees lack management awareness}

From the present logistics enterprises overall development prospect and overall scale, logistics enterprise development is rapid, the scale is huge, the staff is numerous. Employees are distributed at different levels from top to bottom, from management level to basic dispatch staff, and their management awareness is also uneven. At the same time, when enterprises convey corporate task information to basic employees from the top, there is the problem of information circulation and inconsistency in information communication, which makes employees at all levels fail to carry out budget management well and sometimes ignore management, so that management exists only in the form. In addition, there may be unclear understanding of budget management and immature methods at the top of the 
enterprises, which makes the enterprises as a whole lack of staff management awareness.

\subsection{The overall budget management system has a low level of informatization}

With the development of logistics enterprises and the continuous growth of management demands as well as the progress of science and technology, logistics enterprises adopt information systems in order to improve enterprise efficiency and achieve stable and rapid development [9]. Information systems help logistics companies better track and collect and distribute goods, making it easy to obtain and organize information. However, the comprehensive budget management module has not been applied in the information system of many logistics enterprises, and logistics enterprises still use EXCEL forms for manual budget management, but this method cannot meet the requirements of precision of enterprises. This makes the correlation between statements of logistics enterprises very fuzzy, lack of logic; at the same time, each department of the enterprise cannot well share information, which increases the difficulty of communication between each department. Information circulation errors and delay subsequently occur. Therefore, logistics enterprises cannot understand internal details more accurately, make detailed work plans and give instructions. When making plans for the future development of the enterprise, it is also unable to make accurate judgments.

\subsection{Lack of strategic management awareness}

Strategic management emphasizes the whole process in which an enterprise makes a set of measures, which is implemented around the control, operation and decision of the enterprise strategy. If in the process of enterprise comprehensive budget management can fully embody the consciousness of strategic management, on behalf of the enterprises can well for the future planning, forecasting and risk prevention, to become a dynamic and open system of keeping pace with the times, in the face of increasingly fierce market competition, enterprises have strong competitiveness and consciousness, can timely grasp the development direction of whole enterprise, corporate positioning accurately, maintain steady and fast development of enterprise itself [10]. However, in many logistics enterprises, they have not yet noticed strategic management, and their budget targets have not been formulated and implemented in combination with strategic objectives, and have little to do with their own strategic planning. They only consider the annual operating budget, but do not pay attention to the long-term development of the enterprise. The comprehensive budget preparation of logistics enterprises requires the strategic plan and business objectives as the basis, and around the future strategic development plan of the enterprise, step by step and gradually implement the goals, so that the operation and development plan of the enterprise and the comprehensive budget management can be carried out simultaneously.

\subsection{Lack of comprehensive budget control and assessment mechanism}

Some logistics enterprises have not yet worked out the budget evaluation system or have not been implemented, so also failed to give play to its effect. If the reward and punishment system do not apply to the enterprise, there will be unfair performance assessment, which will lead to the failure to mobilize the enthusiasm of employees and reduce the effectiveness of budget assessment. Logistics enterprise comprehensive budget management need to mobilize all the staff, involving all of the departments and business, covering all link of enterprise operation, in order to achieve the most general purpose, namely complete budget target, need to develop effective assessment method of budget, departments and the implementation of the budget and budget targets for comparative analysis. Management goal is the core, comprehensive budget management as a result of the logistics enterprise comprehensive budget management involves the assessment of business objectives, and so on and so forth, an operation period of the business objectives, overall plans, often need to run period after the end of a few months can be issued, this will delay the work of comprehensive budget, budget has been dragged, timeliness are badly affected, directly lead to the current operation phase of the evaluation in budget work.

\subsection{Unclear division of responsibilities for overall budget management}

Full participation, full coverage of business and full coverage of management process are the characteristics of comprehensive budget management [11]. When an enterprise makes a comprehensive budget, in order to ensure its correctness, it should determine the budget target and work task in a certain period in advance, strive to make the work consistent, and promote the successful realization of the overall target of the enterprise. In addition, many grassroots employees do not understand the significance of budget management, think it has nothing to do with themselves, cannot well complete their own work in management. Overall budget management of logistics enterprises should assign clear tasks to management decision-making, implementation and work agencies, so that each agency understands its responsibilities and authority. But due to the complexity of many logistics enterprises business, between the various functional departments is very complex, lead to enterprise only pay attention to the 
financial department of the comprehensive budget management, makes the enterprise comprehensive budget management responsibility and power distribution chaos, lack of close cooperation and support among all departments, at the same time there is fraud, which leads to the lack of correlation between budgeting and actual business, which affects the preparation and implementation of financial budget, and the authority and seriousness of comprehensive budget management are also affected.

\section{SUGGESTIONS ON COMPREHENSIVE BUDGET MANAGEMENT OF LOGISTICS ENTERPRISES}

\subsection{Establish and improve the corporate governance structure}

Comprehensive budget management is a systematic process involving all departments and institutions of logistics enterprises from top to bottom. It includes the achievement of strategic objectives of an enterprise in a certain period and the management of ordinary work of the enterprise. It is the forerunner of all work of the enterprise. Enterprise leadership should have comprehensive management consciousness, attach great importance to the comprehensive budget management and carry out the importance to the entire enterprise, maintain budget authority, and embody the concept and culture of enterprise comprehensive budget management. Then companies of all employees can work actively, find their own talents, and give full play to their enthusiasm and initiative [12]. Every link of daily business activities of logistics enterprises should reflect the sense of comprehensive budget management, strive to achieve the comprehensive budget management objectives set by the enterprise before, so that the implementation efficiency and role of logistics enterprises' comprehensive budget management can be brought into full play.

\subsection{Establish and institutionalize business system standards}

Firstly, logistics enterprises should according to the management method, quantity, production and sales management needs, construct reasonably the comprehensive budget management governance structure in logistics enterprise. From the shareholder level, financial and agencies departments of each link, logistics enterprises delimit the scope of responsibility, clear approval process and work coordinate system and the various functional departments clear own responsibility and obligation, and prompt the implementation of the comprehensive budget management effectiveness. Secondly, logistics enterprises should systematically and logically carry out comprehensive budget management, prepare various budget items and strictly implement and monitor them, constantly modify and adjust the subsequent work in a timely manner, analyze the reasons, and implement a reasonable reward and punishment system. In addition, in the operation activities of logistics enterprises, the annual budget target should follow the development plan, conduct and arrange the action plan of the development strategic target, pay attention to the budget supervision of key projects, and strengthen the supervision of debt risk and the budget of investment.

\subsection{Establish a comprehensive budget control and assessment mechanism}

There are various methods for overall budget control. Logistics enterprises can reasonably use various methods or combine various methods according to their own business characteristics and management needs, so as to bring their own budget control effect into full play. In order to promote the smooth implementation of budget management and mobilize the subjective initiative and enthusiasm of all logistics staff, the assessment and reward and punishment system of comprehensive budget management is a very critical part of the work of logistics enterprises. Logistics enterprises should according to its own positioning and future development vision, according to the specific conditions of different levels of staff, and formulate the corresponding rewards and punishment system, and make each department staff, in the face of the comprehensive budget management instruction can be associated with their own interests, more able to mobilize themselves to work, efforts to achieve personal value and their own interests at the same time satisfy the requirement of the enterprise budget management, the budget evaluation combined with enterprise performance, gradually improve the budget evaluation system, improve the staff's own work and the correlation of corporate interests. It can also build a performance evaluation system for the long-term development of enterprises, provide corresponding rewards and punishments according to the evaluation results, improve the relevance between budget and strategy, and achieve the goal of stable improvement of overall budget management of logistics enterprises.

\subsection{Clarify the division of responsibilities in overall budget management}

Logistics enterprises need comprehensive budget management system and management procedures, and according to the development needs of enterprises at different stages of continuous improvement to improve. Each department should cooperate with each other, not completely independent, timely grasp the index progress, at the same time, the different logistics enterprises should set up corresponding budget management institutions according to their own realities, to 
implement corresponding decision and scientific management and overall budget, make the management of the various agencies coordinate with each other, clear their respective responsibilities and obligations. Senior managers of enterprises should have a comprehensive sense of budget management, pay attention to the cultivation of staff management awareness, give instructions in a timely manner. Managers of all departments should pay attention to the timely and accurate transmission of information from top to bottom, clarify responsibilities and obligations, formulate corresponding budget management reward and punishment system, and reasonably allocate rights and responsibilities.

\subsection{Attach importance to the control of overall budget management}

Due to the numerous and complex business of logistics enterprises, in the process of budgeting, enterprises need to have higher levels of the deep knowledge and understanding, to avoid the employee's work is just walk a form. Only like this can make the budget set by the degree of subjectivity and false negative features reduce. Then implement comprehensive budget management in practice, and during the process practice, constantly improve the comprehensive budget management system.

\section{RESEARCH METHODOLOGY}

Through literature research, this paper combs the definition and meaning of overall budget management. On the basis of the previous research, we visited many logistics enterprises in Sichuan Province to carry out research, visited in the enterprises, through in-depth interviews with logistics enterprises managers and employees, analyzed and summarized the current situation and existing problems of logistics enterprises' overall budget management, and finally put forward some suggestions for development.

\section{CONCLUSION}

Comprehensive budget management on the guarantee enterprises competitiveness and the future development of logistics enterprises and the development orientation of the enterprises is very big. The logistics enterprises need to carry out the work according to the formulation of comprehensive budget and the situation of conducting system of reward and penalties, during the process of thinking highly of the comprehensive budget and the process of continuous improvement. At the same time, in the process of enterprise comprehensive budget management, enterprises should introduce the of advanced information network system to improve management of enterprise budget management level, guide enterprises in the process of forward of the comprehensive budget management to strengthen, and prevent risks in enterprise's future development and management, to make the development of enterprises have more stability, achieve the objectives of the enterprise profit maximization. Logistics enterprises can reasonably use the method of comprehensive budget management to establish the corresponding management system in line with the future development of enterprises. At the same time, the enterprise combines the strategic development goal, sets the goal, strictly implements the comprehensive budget management system in the follow-up work, carries out the reward and punishment. Explore in practice, according to the actual development of the overall budget management system to gradually analyze and adjust, and continue to improve. Only by deeply exploring these problems and strengthening the understanding of the essence of budget management, can the enterprise's overall budget management be strengthened.

\section{REFERENCES}

[1] Y. Li, X. Dai, Construction of enterprise comprehensive budget management system, Enterprise Management. S2(2016) 236-237.

[2] B. Hu, Z. Liu, Characteristics, problems and methods of enterprise organization and management in the internet of things environment, Chinese Management Scienc. 26(8) (2018) 127-137. DOI: 10.16381/j.cnki.issn1003-207x.2018.08.013.

[3] X. Song, Application of comprehensive budget management in cost control of logistics enterprises, Operators. 2020, 34(17), 59-60.

[4] L. Kang, X. Huang, Research on enterprise comprehensive budget management from the perspective of value chain, Accounting Newsletter. 757(29) (2017) 92-96.

[5] G. Qiu, Analysis on financial risks of enterprises [J/OL], Scientific and Technological Economic Market. 05 (2019) 21-23 DOI: http://kns.cnki.net/kcms/detail/36.1122.n.20190701 . 1441.024.html.

[6] R. Cao, Application of total budget management in enterprise internal control, Chinese Market. 19(2019) 78-79. DOI: 10.13939/j.cnki.zgsc.2019.19.078.

[7] Q. Feng, Functional expansion and innovative practice of budget management, Friends of Accounting. 9(2016) 127-133. DOI: 10.3969/j.issn.1004-5937.2016.09.030.

[8] Y. Bao, A Brief Discussion on the budget management mode and monitoring mechanism of 
enterprise management institutions, Finance and Accounting Study. 1(2017) 34, 36. DOI: 10.3969/j.issn.1673-4734.2017.01.022.

[9] L. Song, Discussion on the implementation of comprehensive budget management in enterprises, China Business Review. 34 (2018) 79-80. DOI: 10.19699/j.cnki.issn2096-0298.2018.34.079.

[10] L. Wang, Research on the Operation and Development Strategy of Logistics Enterprises in the E-commerce Environment, Commercial Economics Research. 03(2019) 94-96. DOI: 10.3969/j.issn.1002-5863.2019.03.027.

[11] X. Liang, Optimization Analysis of overall budget management system of logistics enterprises, Operator. 34(10)2020 90, 92

[12] X. Huang, Y. Gao, Countermeasures of China's Intelligent Logistics Development Based on Business Ecosystem Theory, Business Economics Research. 17(2018) 96-98. DOI: 10.3969/j.issn.1002-5863.2018.17.029. 